\title{
Prevalence and predictors of postpartum depression among mothers in the rural areas of Udupi Taluk, Karnataka, India: A cross-sectional study
}

\author{
Anamika Agarwala, P. Arathi Rao*, Prakash Narayanan \\ Prasanna School of Public Health, Manipal Academy of Higher Education, Manipal, India
}

\section{A R T I C L E I N F O}

\section{Keywords:}

Postpartum depression

Risk factors

EPDS scale

\begin{abstract}
A B S T R A C T
Context: Postpartum depression (PPD) is a common affective disorder and is considered as an important public health problem as most of the time it remains unrecognized and affects the health of not only the mother but also the interpersonal relationships, mother-infant bonding as well as emotional and cognitive development of the baby.

Objective: To estimate the prevalence and analyze the factors associated with PPD.

Settings and design: A community based cross-sectional study was conducted in rural areas of Udupi Taluk, Karnataka over a period of six months.

Methods and material: Four hundred ten (410) postnatal women within six months of their deliveries were interviewed using a semi-structured questionnaire, and were screened using Edinburgh Postnatal Depression Scale (EPDS).

Statistical analysis: Descriptive analysis was done on socio-demographic variables, obstetric, neonatal and postnatal and psychosocial factors. Logistic regression was carried to analyze the factors associated with PPD. Results: Prevalence of PPD was 21.5\%. Higher level of maternal and paternal educational status, labour complications, more than two children, history of an abortion and sleeping difficulty of the mothers were found to be statistically significant for PPD.

Conclusion: Early identification of symptoms and timely referral to appropriate health care provider can prevent major depression in the postnatal period.

Key messages: Higher level of educational status of mothers was found to be a risk factor whereas educated fathers were protective for PPD.
\end{abstract}

\section{Introduction}

In developed countries where the infant and maternal mortality rates are low, PPD is given more importance and thus is being considered as a disorder of significant public health concern. However, in developing countries the scenario is totally different. The problem of PPD is often neglected in the community as well as in the health care system. ${ }^{1}$ In India there are a few studies estimated the prevalence and risk factors of PPD which have showed varied findings across culture, region and communities. The prevalence and factors associated with PPD in coastal Karnataka is not known. Also, in rural communities prevalence of PPD is higher worldwide. ${ }^{2}$ So, the objective of this study was to find out the prevalence and identify the predictors of PPD in rural Udupi Taluk, Karnataka. Based on those findings appropriate recommendations can be made to deal with this burden of the problem of the community.

\section{Subjects and methods}

The present cross-sectional study was carried out over a period of six months from January 2016 to July 2016 in the rural areas of Udupi taluk, Karnataka. Ethical approval for this study was obtained by the institutional ethics committee.

Postnatal women, aged 18 years and above registered with the Anganwadi and residing in that area, within six months after delivery who were willing to participate were included in this study. Women with acute severe illness during the same period, and not registered or not residing in the Anganwadi area at the time of the study were excluded from the study. Based on $26.3 \%$ of prevalence of PPD from another study of Tamil Nadu, relative precision of $20 \%$ along with the design effect of 1.5 , the calculated sample size was 410 . For the selection of eligible participants, single stage cluster sampling approach was used. ${ }^{3}$ From the Udupi CDPO office, list of Anganwadi centres was

\footnotetext{
* Corresponding author.

E-mail address: arathimph@gmail.com (P. Arathi Rao).
} 
collected. From the list, the Anganwadi centres were selected randomly using lottery method. The list of registered mothers in the selected anganwadi centre was obtained, and a complete enumeration of postnatal mothers meeting the inclusion criteria were undertaken. Participants were provided the information on the study objectives, purpose of the study, risks and benefits involved in the study in their local language, Kannada, and informed written consent was obtained.

A commonly used screening tool, the Edinburgh Postnatal Depression Scale (EPDS) was used to estimate the prevalence of PPD which is the outcome variable. The EPDS consists of 10 questions; each question scores 0 to 3 depending on the severity with a total score of 30 . It reflects the presence of each symptom during the last 7 days. An EPDS cut off of 10 or more was used in this study as it has been suggested that this cutoff has the highest sensitivity (76\%) and specificity (100\%) for research work. ${ }^{4}$ The Kannada version of EPDS scale was validated by subject experts knowing the local language and used to survey the women for PPD.

Data was collected from 410 postnatal women using a semi structured questionnaire in Kannada. Semi structured questionnaire contained questions on socio-demographic features, possible risk factors including obstetric factors, neonatal and postnatal factors and psychosocial factors which were considered as the predictors of PPD in the present study. After collecting the data, statistical software SPSS-15 was used for data analysis. Descriptive analysis (frequency and percentage) was done on all variables. At first bivariate analysis was carried out and all the factors which had $\mathrm{p}$-value $<0.2$ were considered for multivariable analysis. Logistic regression was used to find the magnitude of the association between factors and PPD. In multivariable analysis, factors which had a p-value $<0.05$ were considered as statistically significant.

\section{Results}

In the study, a total of 410 postnatal mothers were screened for postnatal depression over a period of six months. The results have been presented according to the socio-demographic profile of the study population, obstetrics factors, neonatal and postnatal factors, psychosocial characteristics and the association between the factors and PPD.

Descriptive analysis of socio demographic variables is showed in Table 1. It also showed that all deliveries were conducted in hospital and more than half of them were normal vaginal deliveries (58.3\%). Only $5 \%$ of women had pregnancy and labour complications. Most of their husbands were also educated up to secondary level (46.3\%) and were self-employed (61\%). Regarding the neonatal and postnatal factors, over $90 \%$ of babies were born with a birth weight of $2.5 \mathrm{~kg}$ or more, $34(8.3 \%)$ babies had illness after birth and required hospitalization. Sleeping difficulties were mentioned by 76 mothers $(18.5 \%)$ and $11.2 \%$ of mothers complained about excessive crying of their babies. Most of the women had support of husband, family and social support and less number of women (0.5\%) mentioned about spousal disappointment with sex of the baby when psychosocial factors were considered.

EPDS scoring showed that $88(21.5 \%)$ respondents scored equal to or more than 10 , so they screened positive for PPD. Therefore, prevalence of PPD in this study was $21.5 \%$.

Table 2 shows association between risk factors and PPD. Higher level of education of mothers, presence of labour complications, history of previous abortion, having more than two children and sleeping disturbance of the mothers increased the risk of developing PPD whereas higher level of education of husbands was associated with decreased risk of PPD.

\section{Discussion}

Different studies were done in different parts of the world to find out the association between risk factors and PPD which showed varied
Table 1

Socio-demographic profile of respondents $(n=410)$.

\begin{tabular}{|c|c|}
\hline Variable & Frequency (percentage) \\
\hline \multicolumn{2}{|l|}{ Age of the mother } \\
\hline$<25$ & $90(22.0)$ \\
\hline $25-30$ & $227(55.4)$ \\
\hline$>30$ & $93(22.7)$ \\
\hline \multicolumn{2}{|l|}{ Education } \\
\hline Primary & $54(13.2)$ \\
\hline Secondary & $174(42.4)$ \\
\hline Higher Secondary & $104(25.4)$ \\
\hline Degree & $78(19.0)$ \\
\hline \multicolumn{2}{|l|}{ Occupation } \\
\hline Housewife & $338(82.4)$ \\
\hline service & $72(17.6)$ \\
\hline \multicolumn{2}{|l|}{ Religion } \\
\hline Hindu & $301(73.4)$ \\
\hline Muslim & $91(22.2)$ \\
\hline Christian & $18(4.4)$ \\
\hline \multicolumn{2}{|c|}{ Husband's Education } \\
\hline Primary & 65 (15.9) \\
\hline Secondary & $190(46.3)$ \\
\hline Higher secondary & $81(19.8)$ \\
\hline Degree & $74(18.0)$ \\
\hline \multicolumn{2}{|c|}{ Husband's Occupation } \\
\hline Self employed & $250(61.0)$ \\
\hline Private Service & $152(37.1)$ \\
\hline Govt. Service & $8(2.0)$ \\
\hline \multicolumn{2}{|l|}{ Type of family } \\
\hline Joint & $263(64.1)$ \\
\hline Nuclear & $147(35.9)$ \\
\hline \multicolumn{2}{|c|}{ Monthly income in rupees } \\
\hline$<10,000$ & 85 (20.7) \\
\hline $10,000-20,000$ & $214(52.2)$ \\
\hline$>20,000$ & $111(27.1)$ \\
\hline
\end{tabular}

findings. In this study 410 postnatal mothers from rural Udupi Taluk were involved to calculate the prevalence and identify the risk factors of PPD.

In this study prevalence of PPD was $21.5 \%$. This prevalence of PPD observed in this study was not similar with findings in other studies as shown in Fig. 1. A study conducted at immunization clinics at rural health training centres in rural Bangalore showed a prevalence of PPD using EPDS scale as $11.47 \% .{ }^{11}$ In another prospective cohort study conducted at Chhainsa, Haryana among 200 pregnant women in 3rd trimester and followed up till 6 weeks postpartum period, the prevalence of PPD using EPDS scale was found to be $12 \% .{ }^{14} \mathrm{~A}$ study in a tertiary care hospital in rural Mandya district of Karnataka, was conducted among 102 postpartum women revealed the prevalence of PPD was $31.4 \%{ }^{3}$ In another study conducted at the district hospital, Goa, among 270 mothers it was found that the prevalence of PPD was $23 \%$ at 6 weeks postpartum. ${ }^{12}$

Educational status of the mother was found to be a risk factor for PPD in this study. It showed that higher level of education of the mothers increased the odds of developing PPD. It was 9-17 times more in secondary, higher secondary and degree level when compared to primary level. It might be due to the fact that educated women were more involved in outside work (service), so got less time to manage the baby as well as the household work. Work related stress might be also a contributor. Educated women might have understood the symptoms and provided required information during screening by EPDS scale. A study done by Wolf et al. in Costa Rica showed that postpartum dysphoria was associated with higher level of educational status of mothers. ${ }^{5}$ This finding was explained by the fact that educated mothers 
Table 2

Factors associated with PPD.

\begin{tabular}{|c|c|c|c|c|}
\hline Variable & Depressed $n=88(\%)$ & Not Depressed n = $322(\%)$ & Unadjusted OR (95\% CI), p value & Adjusted OR (95\% CI) \\
\hline \multicolumn{5}{|l|}{ Education } \\
\hline Primary & $8(9.1)$ & $46(14.3)$ & 1 & 1 \\
\hline Secondary & $33(37.5)$ & $141(43.8)$ & $1.346(0.58-3.12),(\mathrm{p}=0.290)$ & $9.946(2.078-47.59)$ \\
\hline Higher Secondary & $29(33)$ & $75(23.3)$ & $2.223(0.937-5.27),(\mathrm{p}=0.065)$ & $17.01(2.946-98.25)$ \\
\hline Degree & $18(20.5)$ & $60(18.6)$ & $1.725(0.689-4.31),(p=0.700)$ & $12.02(1.597-90.51)$ \\
\hline \multicolumn{5}{|c|}{ Husband's Education } \\
\hline Primary & $10(11.4)$ & $55(17.1)$ & 1 & 1 \\
\hline Secondary & $49(55.7)$ & $141(43.8)$ & $1.911(0.905-4.03),(\mathrm{p}=0.047)$ & $0.72(0.223-2.32)$ \\
\hline Higher Secondary & $12(13.6)$ & $69(21.4)$ & $0.957(0.385-2.37),(\mathrm{p}=0.104)$ & $0.203(0.042-0.0 .99)$ \\
\hline Degree & $17(19.3)$ & $57(17.7)$ & $1.64(0.691-3.89),(\mathrm{p}=0.727)$ & $0.636(0.12-3.38)$ \\
\hline \multicolumn{5}{|c|}{ Labour complications } \\
\hline No & $69(78.4)$ & $318(98.8)$ & 1 & 1 \\
\hline Yes & $19(21.6)$ & $4(1.2)$ & $21.891(7.22-66.37),(p<0.001)$ & $10.715(0.915-125.49)$ \\
\hline \multicolumn{5}{|l|}{ Abortion } \\
\hline No & $73(83)$ & $308(95.7)$ & 1 & 1 \\
\hline Yes & $15(17)$ & $14(4.3)$ & 4.521 (2.089-9.78), (p < 0.001) & $4.446(1.308-15.11)$ \\
\hline \multicolumn{5}{|l|}{ Child Number } \\
\hline Upto two & $76(86.4)$ & $304(94.4)$ & 1 & 1 \\
\hline More than two & $12(13.6)$ & $18(5.6)$ & 2.667 (1.232-5.77), $(\mathrm{p}<0.001)$ & 3.657 (1.115-11.99) \\
\hline \multicolumn{5}{|c|}{ Sleep disturbance of mother } \\
\hline No & $28(31.8)$ & $306(95)$ & 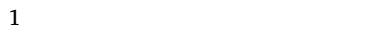 & 1 \\
\hline Yes & $60(68.2)$ & $16(5)$ & 40.98 (20.89480.385), $(\mathrm{p}<0.001)$ & $38.567(13.866-107.27)$ \\
\hline
\end{tabular}

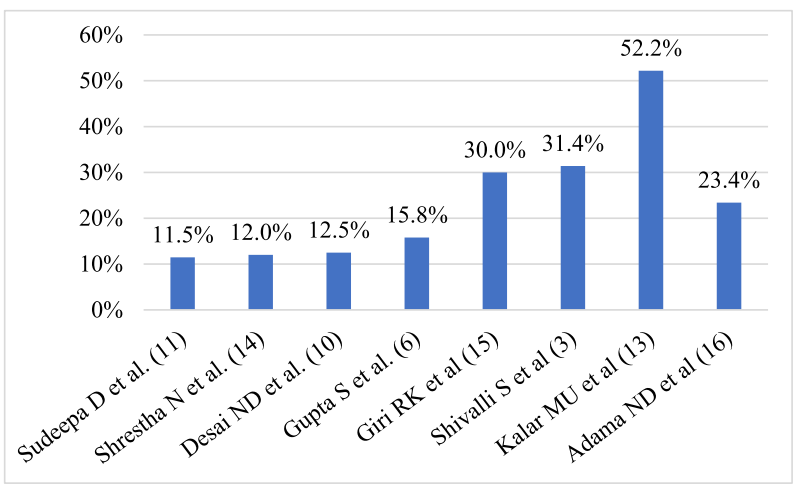

Fig. 1. Prevalence of PPD in different studies. ${ }^{3,6,10,11,13-16}$

recalled detailed information up to 5 years after child birth regarding postpartum dysphoria. In contrast to this study, low educational status was found to be a risk factor for PPD by Gupta et al. in Delhi. In that study it was attributed that women with low educational status were not able to think logically and were unable to take decision both emotionally and economically. ${ }^{6}$

Higher level of education of husbands was found to be negatively associated with PPD. The adjusted ORs for secondary, higher secondary and degree levels were $0.7(0.22-2.32), 0.20(0.042-0.0 .99)$ and 0.64 (0.12-3.38) respectively, so it acted as a protective factor for PPD. It might be due to the increased level of knowledge regarding PPD among men. As the men understood the problem so they could help women in their coping strategies. A study done in Turkey by Inandi et al. ${ }^{7}$ found the similar result.

The women with labour complications were 10.7 times (95\%CI: 0.92-125.49) more likely to develop PPD. Among the 23 women who had labour complications, 19 (82.6\%) screened positive for PPD. In a study conducted by Nasreen et al. in Bangladesh showed that the odds for developing depression was three times higher (adjusted odds ratio $=3.11, \mathrm{p}=0.002$, CI 1.52-6.36) for women with negative childbirth experiences after delivery than women with no negative childbirth experiences which was consistent with this study finding. ${ }^{8}$
Labour complications were found to be a risk factor in another study done by Mathisen et al. in Argentina. ${ }^{9}$

Out of 410 respondents 29 (7.1\%) had history of abortion and out of these 29 women more than half of the women (51.7\%) developed PPD. According to this study women with previous history of abortion were 4.4 (95\% CI: 1.31-15.11) times more likely to develop PPD. The odds of developing depression were 3 times higher in women with two or more children (adjusted OR of 3.7; 95\% CI: 1.12-11.99). These two findings are consistent with a study done by Desai et al. among 200 women in Gujarat. ${ }^{10}$ In that study multigravida were seen to be 5.4 times more likely to develop depression than the primigravida and if the woman had any previous history of miscarriage, the odds that such a female becomes depressed was 4.6 times higher than a woman without any miscarriage.

Another important factor for developing PPD was sleeping disturbance of the mother. It had an adjusted OR of 38.6 (95\%CI: 13.87-107.27), so the mothers who had sleeping disturbance were 38.5 times more predisposed to develop PPD. Similar finding was observed in a study done by Sudeepa et al. in rural Bangalore. ${ }^{11}$

Patel et al in 2001 found that in the Indian setting most common psychosocial factors which predisposed women to develop PPD were preference to male child, violence against women, poverty and lack of social support. ${ }^{12}$ However, none of those factors was found to be a risk factor for PPD in this study. Planned pregnancy, family support and support of the husband were found to be protective factors in a study done by Kalar et al. in Karachi, but in this study those factors were not found to be significant. ${ }^{13}$

The prevalence and risk factors of PPD as estimated by the present study is based on self-reported depressive symptoms collected through EPDS scale and not confirmed diagnostically.

\section{Conclusion}

More than one fifth of postnatal women develop signs and symptoms of PPD. Women who have undergone complicated labour, previous abortions, having more than 2 childbirths and sleeping disturbances need to be screened during the postnatal follow-ups and family members should be educated to seek medical attention if signs 
and symptoms of depression appear.

\section{Acknowledgement}

Authors would like to thank mothers who participated in the study, the anganwadi teachers and the ASHA workers who helped during data collection.

\section{References}

1. Beck CT. Postpartum depression: it isn't just the blues. Am J Nurs. 2006;106(5):40-50

2. Mollard E, Hudson DB, Ford A, Pullen C. An integrative review of postpartum depression in rural U.S. Communities. Arch Psychiatr Nurs. 2016;30(3):418-424.

3. Shivalli S, Gururaj N. Postnatal depression among rural women in south India: do socio-demographic, obstetric and pregnancy outcome have a role to play? PLoS One. 2015;10(4):e0122079.

4. Cox JL, Holden JM, Sagovsky R. Detection of postnatal depression: development of the 10-item Edinburgh postnatal depression scale. Br J Psychiatry. 1987;150:782-786.

5. Wolf AW, De Andraca I, Lozoff B. Maternal depression in three Latin American samples. Soc Psychiatr Psychiatr Epidemiol. 2002;37(4):169-176.

6. Gupta S, Kishore J, Mala Y, Ramji S, Aggarwal R. Postpartum depression in North indian women: prevalence and risk factors. $J$ Obstet Gynaecol India 2013;63(4):223-229.

7. Inandi T, Elci C, Ozturk A, Egri M, Sahin TK. Risk factors for depression in postnatal first year, in eastern Turkey. Int J Epidemiol. 2002;31(6):1201-1207.

8. Nasreen H-E, Edhborg M, Petzold M, Forsell Y, Kabir ZN. Incidence and risk factor of postpartum depressive symptoms in women: a population based prospective cohort study in a rural district in Bangladesh. J Depress Anxiety. 2015;4(2):180-188.

9. Mathisen SE, Glavin K, Lien L, Lagerlov P. Prevalence and risk factors for postpartum depressive symptoms in Argentina: a cross-sectional study. Int $J$ Womens Health. 2013;5:787-793.

10. Desai ND, Mehta RY, Ganjiwale J. Study of prevalence and risk factors of postpartum depression. Natl J Med Res. 2012;2(2):194-198.

11. Sudeepa D, Madhukumar S, Gaikwad V. A study on postnatal depression of women in rural Bangalore. Int J Health Sci Res. 2013;3(1):1-6.

12. Patel V, Rodrigues M, DeSouza N. Gender, poverty, and postnatal depression: a study of mothers in Goa, India. Am J Psychiatr. 2002;159(1):43-47.

13. Kalar MU, Fatima I, Nabila K, et al. Prevalence and predictors of postnatal depression in mothers of Karachi. Int J Collab Res Intern Med Public Health. 2012;4(5):830-837.

14. Shrestha N, Hazrah P, Sagar R. Incidence and prevalence of postpartum depression in a rural community of India. Journal of Chitwan Medical College. 2015;5(2):11-19.

15. Giri RK, Khatri RB, Mishra SR, Khanal V, Sharma VD, Gartoula RP. Prevalence and factors associated with depressive symptoms among post-partum mothers in Nepal. BMC Res Notes. 2015;8:111.

16. Adama ND, Foumane P, Olen JPK, Dohbit JS, Meka ENU, Mboudou E. Prevalence and risk factors of postpartum depression in Yaounde, Cameroon. Open J Obstet Gynecol. 2015;5(11):608-617. 